\title{
APRESENTAÇÃO
}

\section{INTERPRETAÇÕES DO BRASIL E DILEMAS CONTEMPORÂNEOS}

\author{
Karim Helayel \\ Beatriz, Malcher ${ }^{2}$ \\ Maria Caroline M. Tresoldi ${ }^{3}$
}

De fato, quando imaginava qual poderia ser um comentário consistente a "por que pensar o Brasil?", o primeiro argumento que me veio à mente foi: porque se não o fizermos ninguém o fará - Gildo Marçal Brandão, Linhagens do pensamento político brasileiro.

É com imensa satisfação que trazemos a público o dossiê Interpretações do Brasile dilemas contemporâneos, que reúne trabalhos de jovens pesquisadores de diversas áreas das ciências humanas, cujas reflexões estabelecem diálogos com aquelas que se convencionaram chamar de "interpretações

\footnotetext{
${ }^{1}$ Pesquisador de pós-doutorado no Programa de Pós-Graduação em Sociologia e Antropologia da Universidade Federal do Rio de Janeiro (PPGSA/UFRJ). É mestre e doutor pela mesma instituição. E-mail: khelayel@gmail.com. Orcid: https://orcid.org/0000-0002-5680-4556.

${ }^{2}$ Pesquisadora de pós-doutorado no Programa de Pós-Graduação em Ciência da Literatura da Universidade Federal do Rio de Janeiro, doutora em Teoria Literária pela referida instituição e mestre em Mídia e Mediações Socioculturais pelo Programa de Pós-Graduação em Comunicação e Cultura da UFRJ. E-mail: malcher.beatriz@gmail.com. Orcid: https://orcid. org/0000-0003-4077-3860.

${ }^{3}$ Mestre em Sociologia pelo Programa de Pós-Graduação em Sociologia da Universidade Estadual de Campinas. Bacharela e Licenciada em Ciências Sociais pela mesma universidade. Editora da revista Temáticas. E-mail: carolinetresoldi@gmail.com. Orcid: https://orcid. org/0000-0001-8218-5181.
} 
do Brasil". Enquanto organizadores do dossiê, nossa aposta consistiu em "testar" o repertório cognitivo das interpretações produzidas sobre o país, de modo a perscrutar os dilemas que se encontram postos na sociedade brasileira contemporânea, que passou por diversas transformações nas últimas décadas e vive, desde pelo menos 2013, um quadro de crise política e social, a qual se somou uma crise econômica a partir de 2015 e, nesse último ano, uma crise sanitária causada pelo novo coronavírus.

O "teste" proposto foi procedido de modo interdisciplinar, uma vez que os trabalhos publicados no presente dossiê reúnem esforços de pesquisadores provenientes da Ciência Política, Comunicação, Filosofia, História, Linguística, Sociologia e Teoria Literária. Desse modo, não custa lembrar que, malgrado o estudo dos intelectuais e de suas interpretações sobre o Brasil ser considerado aspecto constitutivo da reflexão sociológica produzida no país, o Pensamento Social não seria objeto restrito a um campo disciplinar específico (BASTOS; BOTELHO, 2010). Sendo assim, os manuscritos que compõem o dossiê contribuem para reforçar a tônica de que o estudo das interpretações do país não se limita a uma especialização em particular, interpelando pesquisadoras e pesquisadores situados em diversos campos do conhecimento, que possuem o interesse em compreender e explicar a dinâmica da sociedade brasileira em suas diferentes esferas.

Contudo, entendemos que não constitui tarefa das mais simples aproximar textos considerados clássicos, confeccionados em tempos pretéritos, de nossas preocupações mais candentes na atualidade. Tal movimento pode implicar em certos perigos, dentre os quais, podemos destacar o de recairmos na tentação do anacronismo, perigo esse que, em alguma medida, jamais é descartado quando é tentada a aproximação entre textos clássicos e questões contemporâneas, mas que é, por outro lado, passível de controle (BOTELHO, 2019a). Ou seja, esse é um desafio a ser enfrentado e em relação ao qual as reflexões apresentadas no dossiê não se furtaram, mobilizando, de diferentes modos, as interpretações do país como recurso analítico para o entendimento de alguns de nossos impasses contemporâneos. Se, de um lado, constitui imperativo compreender as grandes constelações de ideias levando em conta os problemas históricos 
aos quais procuraram responder, bem como as formas e procedimentos em que são formuladas e discutidas, por outro, nenhuma delas pode ser completamente resolvida em seu próprio contexto (BRANDÃO, 2007). Portanto, a contrapelo de perspectivas que enxergam o recurso às interpretações do Brasil como mero exercício estéril de erudição, ou mais comumente como uma espécie de "conhecimento antiquário", concordamos com as formulações que se contrapõem a tais visões, destacando sua importância tanto para a sociedade quanto para as Ciências Sociais contemporâneas (SCHWARCZ; BOTELHO, 2009; BOTELHO, 2019a; MAIA, 2018).

Nessa apresentação, procuraremos discutir algumas questões suscitadas ao longo do processo de construção do dossiê, as quais serão tratadas em dois momentos distintos. $\mathrm{O}$ primeiro diz respeito à própria noção de "interpretações do Brasil", amplamente debatida pela fortuna crítica, de modo a chamar a atenção para a sua relevância teórica na contemporaneidade e discutir o estatuto da área de Pensamento Social no Brasil na atualidade, que vem crescendo nas últimas décadas, e tem entre seus principais objetos de estudo as ideias e os intelectuais que pensaram o país em diferentes contextos. Já em um segundo momento, trataremos mais diretamente de alguns dilemas contemporâneos, tendo em vista principalmente o desafio de articulação das questões contemporâneas a autores considerados clássicos, que pensam o capitalismo e a modernidade a partir da periferia. Após essas considerações, realizaremos uma breve apresentação dos artigos que compõem o presente dossiê.

\section{DECODIFICAR E INTERPRETAR O BRASIL: DESAFIO PERENE}

Afirmar que os chamados "ensaios de interpretação do Brasil", especialmente aqueles produzidos por Oliveira Vianna, Gilberto Freyre, Sérgio Buarque de Holanda e Caio Prado Júnior vêm informando as mais distintas gerações de intelectuais não constitui novidade. Podemos lembrar aqui do clássico prefácio de Antonio Candido (1995), preparado para a quinta edição de Raízes do Brasil (1936), de Sérgio Buarque de Holanda, no qual o crítico literário chama a atenção para os impactos intelectuais 
distintos de livros como Casa-grande \& senzala (1933), o próprio Raízes do Brasil e Formação do Brasil contemporâneo (1942) sobre a juventude dos anos 1933-1942. Importância também conferida, mais recentemente, por Fernando Henrique Cardoso (2013), que, ao retornar a essas formulações que "inventaram o Brasil", concede ênfase à leitura dos trabalhos seminais de Gilberto Freyre, Sérgio Buarque de Holanda e Caio Prado Jr., e reafirma, nesse sentido, o importante lugar ocupado pelos "ensaios de interpretação do Brasil" em nossa tradição intelectual, constatando que "de modo muito diverso esses três autores procuraram, no fundo, dar uma resposta sobre a questão de nossa identidade, sobre as condicionantes da história e as alternativas de futuro do Brasil"' (CARDOSO, 2013, p. 284).

No entanto, como é sabido, o esforço ensaístico de análise da formação social brasileira não se esgota naqueles ensaios originários de interpretação do país - ainda que tal gênero de reflexão tenha se tornado escasso dada a especialização acadêmica que se seguiu (CARDOSO, 2013; CHALOUB; LIMA, 2018). ${ }^{4}$ O livro A revolução burguesa no Brasil (1975), de Florestan Fernandes, é qualificado pelo próprio autor como um "ensaio de interpretação sociológica", destoando de seus trabalhos anteriores (RICUPERO, 2008). Ensaio esse que pode ser qualificado como marcadamente "cosmopolita", cuja capacidade de interpelação não se limitou ao seu contexto imediato, haja vista a potência da categoria "autocracia burguesa", que pode auxiliar não somente a entender contextos periféricos, como também a dinâmica mais ampla do capitalismo a nível global (BOTELHO; BRASIL JR., 2020). Diagnóstico em linha semelhante pode ser encontrado em trabalho recente de Elide Rugai Bastos (2020), que chama a atenção para a atualidade da categoria "circuito fechado", proposta também por Florestan Fernandes, cuja relevância não se circunscreve apenas à periferia do capitalismo, posto que diz respeito também a situações de exclusão que vêm ocorrendo em

\footnotetext{
${ }^{4}$ Não constitui redundância assinalar que Gildo Marçal Brandão (2007, p. 156) chama a atenção, ao discutir os percalços da perspectiva institucionalista, para os problemas decorrentes da "tecnificação da atividade intelectual" e para a fragmentação disciplinar em inúmeras especialidades, aspectos que "acabam por bloquear a possibilidade de pensar o conjunto, reduzem a reflexão à expressão reificada do próprio processo social”.
} 
outras partes do mundo, permitindo afirmar "que a periferia não está apenas no hemisfério sul, não é dado territorial, mas refere-se às margens da sociedade" (BASTOS, 2020, p. 684). ${ }^{5}$

Não são poucas as questões trabalhadas pelos ensaístas e cientistas sociais pioneiros que se rotinizaram, a exemplo da categoria weberiana "patrimonialismo" - mobilizada com ênfases distintas por nossa tradição intelectual (WERNECK VIANNA, 1999) -, cuja ressonância no debate público brasileiro não é nada desprezível (WERNECK VIANNA, 2009; RICUPERO, 2017; BOTELHO, 2019b). Não à toa, Bernardo Ricupero (2017) assinala que o “patrimonialismo está no ar", uma vez que os editoriais e colunas da grande imprensa têm se utilizado do conceito com alguma frequência para lidar com a confusão entre as esferas pública e privada, ${ }^{6}$ no intuito de formular explicações para a corrupção endêmica no país. Levando em consideração a apropriação e mobilização indiscriminada do conceito no debate público, André Botelho (2019b) sustenta que, malgrado se associarem na prática, "patrimonialismo" e "corrupção" não seriam categorias intercambiáveis. De um lado, argumenta, por vir sendo tão amplamente apropriado, o conceito de "patrimonialismo" vem se tornando inespecífico, e por outro, "vai assumindo quase um sentido de categoria de acusação: é um pecado/crime cometido pelo ‘outro' - não pelo sujeito da enunciação” (BOTELHO, 2019b, p. 276). Para não nos alongarmos no exemplo, gostaríamos de indicar que as formulações daqueles que são considerados intérpretes do país têm agência e ressonância, uma vez que as categorias por eles forjadas são recorrentemente mobilizadas no debate público.

Ressaltamos, então, que essas possibilidades de comunicação entre aqueles que entendemos como nossos clássicos e as preocupações que vêm nos acometendo na contemporaneidade tem sido tratada com alguma recorrência pela fortuna crítica, especialmente aquela vinculada à área do Pensamento Social no Brasil. Como já discutiram Elide Rugai Bastos e

\footnotetext{
${ }^{5}$ Aspecto reafirmado por Elide Rugai Bastos em entrevista concedida a Karim Helayel e Maria Caroline M. Tresoldi, a qual compõe o presente dossiê.

${ }^{6}$ Para uma análise pormenorizada sobre a problemática do baralhamento entre público e privado na sociologia política brasileira, conferir Botelho, 2019a.
} 
André Botelho (2010), um dos vezos mais significativos com base no qual o Pensamento Social vem se consolidando enquanto campo de estudos se refere justamente às pesquisas sobre aqueles que seriam os nossos clássicos. Procurando responder à questão relativa à importância da aproximação das interpretações produzidas no passado e os problemas do nosso presente, os autores sugerem que os desafios atuais que se apresentam a qualquer sociedade se encontram imbricados ao caráter diacrônico do processo social. Além disso, Bastos e Botelho apontam que o processo social tratado pelos clássicos brasileiros se encontra aberto em diversos sentidos, fazendo com que suas formulações ainda tenham capacidade para nos interpelar cognitivamente no presente. As relações políticas e sociais em curso na sociedade brasileira nos conduzem, dessa maneira, a retornar às interpretações forjadas no passado, uma vez que, malgrado sejam inúmeros os ganhos das Ciências Sociais institucionalizadas, não existiriam "razões suficientes para superestimá-los como se tivessem permitido resolver de modo permanente os problemas que os ensaístas ou os cientistas sociais das gerações anteriores levantaram" (BASTOS; BOTELHO, 2010, p. 493).

No artigo "Passado futuro dos ensaios de interpretação do Brasil", recolhido no livro O retorno da sociedade, André Botelho (2019a) procura problematizar a unidade comumente atribuída ao chamado "ensaísmo de interpretação do Brasil". Ao não enfatizar os traços comuns entre os distintos ensaios de interpretação do país, confeccionados entre os anos 1920-1940, Botelho (2019a, p. 203) chama a atenção para o papel que eles ocupam na cultura intelectual brasileira, "ligando o passado, o presente e o futuro". O autor procura contribuir para a desestabilização do processo de domesticação dos ensaios de interpretação do Brasil em torno da problemática da "identidade nacional", processo esse não raras vezes reificado pela fortuna crítica e que aparece em alguma medida, como pudemos observar, na leitura de Cardoso (2013). O "ensaísmo" e as "interpretações do Brasil" não constituem, no argumento de Botelho (2019a, p. 219), "realidades ontológicas estáveis", posto que seriam, sobretudo, "objetos de disputas cognitivas e políticas e, nesse sentido, recursos abertos e contingentes, ainda que não aleatórios, no presente". 
Nessa linha, podemos dizer que os ensaios de interpretação do Brasil - e, aqui, podemos acrescentar os trabalhos das gerações pioneiras das Ciências Sociais institucionalizadas - operam reflexivamente, "desde dentro, como um tipo de metalinguagem da própria sociedade brasileira, como uma semântica histórica que participa da configuração de processos sociais mais amplos, como o da construção do Estado-nação" (BOTELHO, 2019a, p. 217).

Se nos remetermos ao texto de apresentação do dossiê Interpretações do Brasil contemporâneo, da revista Mediações, organizado por Jorge Chaloub e Pedro Luiz Lima (2018), podemos constatar a preocupação dos pesquisadores com a qualificação da categoria "interpretação do Brasil". Os organizadores destacam, em particular, o "caráter híbrido" da categoria, a qual comportaria três características fundamentais, a saber, sua "pretensão de totalidade", sua interdisciplinaridade e a preocupação com a "intervenção na conjuntura". A marca das interpretações do Brasil seria, desse modo, uma diversidade que não pode ser confinada a determinados contextos históricos e intelectuais ou campos específicos do conhecimento. A atenção de Chaloub e Lima (2018, p. 34) se volta, em particular, para a relação entre a construção de interpretações do Brasil contemporâneo e a questão da democracia. Não haveria, sustentam, "interpretação possível do Brasil contemporâneo que não passe pela questão da democracia".

Concordando com esse argumento, essa é uma questão que aparece também no dossiê Interpretações do Brasil e dilemas contemporâneos, uma vez que boa parte dos esforços nele presentes indicam a importância do debate racial. Não podemos esquecer que Florestan Fernandes ressalta, ao analisar a problemática referente à precária integração de negras e negros na "ordem social competitiva", os limites da democracia liberal-burguesa entre nós (BASTOS, 1987), esforço que parece orientar boa parte dos trabalhos aqui publicados. A ênfase conferida à questão racial por boa parte dos artigos parece reiterar os limites de realização da democracia no Brasil contemporâneo, haja vista os processos de violência e exclusão perpetrados contra a população negra, o que coloca em xeque ainda o sentido assumido pelo desenvolvimento capitalista no país. Tendo como ponto de partida a questão racial, veremos como os manuscritos 
recuperam questões desenvolvidas em clássicas interpretações do país e buscam ampliar o que até hoje elegemos como cânones, construindo seus diálogos com intelectuais como Abdias do Nascimento, Clóvis Moura, Lélia Gonzalez e Sueli Carneiro, além de artistas como Emicida e o grupo Racionais MC's.

A necessidade de incorporar ao cânone das interpretações do Brasil novos trabalhos que ampliem nossa capacidade de pensar os impasses do país, é assinalada, em alguma medida, por André Botelho e Lilia Schwarcz, organizadores da coletânea Um enigma chamado Brasil (2009). Os autores apontam, na apresentação do livro, que a eleição de 29 intérpretes implica, inevitavelmente, em "seleções e esquecimentos". A inclusão de novos intelectuais e de novas interpretações indica, assim, "a recorrência e a vitalidade com que a sociedade brasileira vem sendo continuamente pensada" (BOTELHO; SCHWARCZ, 2009, p. 15). Afinal, as interpretações do país se tornam matrizes que codificam modos distintos de pensar, sentir e agir no país. Elas não operam somente em termos cognitivos, mas se constituem também como "forças sociais" que "direta ou indiretamente contribuem para delimitar posições e conferir-lhes inteligibilidade em diferentes disputas de poder travadas na sociedade" (BOTELHO; SCHWARCZ, 2009, p. 13).

Nessa direção, é importante ressaltar, como discute Antonio Brasil Jr. (2015), a importância da agenda de pesquisa de Elide Rugai Bastos, que conjuga a reflexão sobre os efeitos sociais e políticos das ideias no processo de constituição da formação social brasileira e a análise sobre o modo pelo qual as categorias construídas pela intelectualidade parecem acompanhar o movimento mais geral da sociedade. Isso se exprime com clareza, por exemplo, nas formulações de Bastos em As criaturas de Prometeu (2006), cuja hipótese é a de que a interpretação de Gilberto Freyre teria sido decisiva como componente intelectual para o pacto agrário-industrial da década de 1930, ou seja, para a constituição e legitimação do bloco de poder naquele momento histórico.

Incorrendo no risco de sermos reiterativos, podemos dizer que a perenidade das reflexões tecidas pelas e pelos intérpretes do país não se confinam ao momento histórico em que foram produzidas em virtude 
de sua agência e de seus efeitos políticos e sociais para a modelagem do plano social. Ou seja, além de informar o debate público, as ideias podem lograr efetividade por meio de sua internalização em perspectivas políticas e visões de sociedade, problemática que aparece de maneira decisiva em diferentes trabalhos de Elide Rugai Bastos, inclusive na entrevista que ela gentilmente concedeu para este dossiê. Em outras palavras, como a análise dos processos sociais não se resolve apenas por meio de uma ênfase nos planos político e econômico, o estudo das ideias se afigura incontornável (MAIA, 2015).

Convém, ainda, notar mais um dado relevante sobre as interpretações do país: estamos prestes a completar o bicentenário de Independência (1822-2022) em um momento de grande tensão social e política, no qual nos perguntamos não apenas "por que pensar o Brasil?", mas também “o que é o Brasil?”. Em momentos de grandes tensões, como indica Bastos (2002) em seus estudos sobre Florestan Fernandes, a crise pode servir como ferramenta heurística para compreender o movimento da sociedade em seu conjunto. No entanto, durante as crises, categorias como "interpretações do Brasil", "intelectuais", dentre outras, correm o risco de se tornarem mais instáveis. Se a crise tem uma dimensão heurística, por assim dizer, o Brasil se torna uma categoria problemática, e talvez até mesmo programática, de modo que as fabulações sobre o país ficam em constante disputa e são objetos de elaboração de diferentes grupos sociais. ${ }^{7}$ No caso dos trabalhos que compõem este dossiê, como discutiremos de modo mais detido, revelase o interesse de jovens pesquisadores por novas fabulações que, sem ignorar a teorização do que entendemos como clássicos, podem abrir uma perspectiva, na qual a "comunicação entre presente, passado e futuro" pode oferecer de fato "uma visão mais integrada e consistente da dimensão de

\footnotetext{
${ }^{7}$ Podemos citar como exemplo a iniciativa "Pensadores do Brasil" do Instituto General Villas Bôas, que desde 2020 vem se organizando para publicar mais de 200 livros até o Bicentenário da Independência do Brasil. Na página do instituto na internet, lê-se a intenção do idealizador da iniciativa, o próprio General Villas Bôas: "este trabalho é o início de um projeto muito maior - um Projeto de Nação. Queremos resgatar grandes pensadores para que as novas gerações conheçam suas ideias e vejam-se, portanto, como cidadãos estratégicos e atuantes na construção do Brasil que merecemos". Link para acesso: https://igvb.org/colecao-de-livros/. Acesso em 12 de jun. 2021.
} 
processo que nosso presente ainda oculta" (BOTELHO; SCHWARCZ, 2009, p. 15, grifos no original). Trata-se de uma visada que, sem dúvida, procura pensar o potencial heurístico da crise e disputar visões sobre o Brasil contemporâneo.

Problematizando a categoria de interpretações do Brasil, convém agora indicar algumas características da área mais conhecida como Pensamento Social no Brasil. Diversos balanços bibliográficos vêm apontando um processo de institucionalização e consolidação dessa área de estudos nas últimas décadas (BOTELHO, 2019a). João Marcelo Maia (2011, p.78) a define, por exemplo, como "campo de estudos contemporâneo voltado para a investigação de nossa tradição intelectual erudita". Ou seja, as interpretações do país discutidas até aqui configuram, em larga medida, a matéria prima de pesquisa do Pensamento Social no Brasil.

Em "O pequeno grande mundo do Pensamento Social no Brasil", Antonio Brasil Jr., Luiz Carlos Jackson e Marcelo Paiva (2020) fazem um amplo balanço da área. ${ }^{9}$ Os autores sugerem que a criação do Grupo de Trabalho em Pensamento Social no Brasil na Associação Nacional de PósGraduação e Pesquisa em Ciências Sociais (ANPOCS), em 1983, pode ser considerado um de seus marcos fundadores. Mas é entre as décadas de 1990 e 2000 que novas gerações de cientistas sociais, já especializados,

\footnotetext{
${ }^{8}$ Vale notar que a atenção que a área vem recebendo não se reduz aos círculos especializados, mas também a públicos amplos, como sugere a publicação de diversas coletâneas ou biografias de escritores e intelectuais, voltadas para não acadêmicos (BOTELHO; SCHWARCZ, 2009). Podemos ainda mencionar a iniciativa da Biblioteca Virtual do Pensamento Social, que é uma rede construída para atuar, como destaca André Botelho (2019a, p.252), em três esferas: i) produção de conhecimento; ii) memória do acervo do pensamento social e de tradições intelectuais; iii) subsídios didáticos-pedagógicos e divulgação científica. No último caso, recomendamos uma consulta ao Blog da BVPS, espaço importante de divulgação científica da área de Pensamento Social. Ver: https://blogbvps.wordpress.com/.

${ }^{9}$ Outros balanços recentes sobre o campo podem ser encontrados em Josiowicz e Brasil Jr. (2019), trabalho dedicado ao estudo de caso da Biblioteca Virtual do Pensamento Social, e Carvalho e Brasil Jr. (2020), pesquisa sobre a produção de artigos na área de Pensamento Social no Brasil. Vale observar que, em parceria, Antonio Brasil Jr. e Lucas Carvalho vêm se utilizando de ferramentas bibliométricas para mapear a produção da área, com vistas a tecer considerações sobre seus alcances e desafios.
}

Temáticas, Campinas, 29, (57): 09-37, fev./jun. 2021 
passaram a reivindicar mais enfaticamente o Pensamento Social no Brasil como área de pesquisa. Parte dos membros dessa geração, como indica o referido balanço, foi se legitimando como intérprete do pensamento de intelectuais e escritores pioneiros, ou pelo estudo de movimentos intelectuais e artísticos. É claro que, como em qualquer área, nesse processo de institucionalização conviveram posições teóricas e metodológicas muito distintas, e até mesmo concorrentes. ${ }^{10}$ Seja como for, o que interessa observar é que a investigação da formação nacional, dos processos de mudança social, da relação entre intelectuais e vida política, do processo de institucionalização das Ciências Sociais no Brasil etc. foram alguns dos principais temas tratados pelos primeiros praticantes da área.

As gerações mais recentes de pesquisadores e de pesquisadoras têm partido desses estudos iniciais e procurado ampliar as possibilidades de pesquisa. Vemos hoje um notável interesse, por exemplo, por autoras e autores menos estudados e consagrados; pela produção intelectual e artística mais contemporânea; além de prevalecer uma diversidade metodológica nas atuais agendas de pesquisa (BRASIL JR.; JACKSON; PAIVA, 2020). Os manuscritos reunidos no presente dossiê, como veremos, nem sempre inserem seus debates na área de Pensamento Social no Brasil, mas suas pesquisas - que retomam ideias, intelectuais e artistas, bem como conceitos analíticos forjados pela intelectualidade brasileira certamente dialogam com questões, temas e problemas mais amplos da área.

Alguns estudos recentes também vêm procurando acentuar a atualidade do Pensamento Social no Brasil no quadro mais amplo das Ciências Sociais contemporâneas. Segundo João Marcelo Maia (2018), o relativo sucesso da área nas últimas décadas esconde o fato de que ela é seriamente questionada e criticada por colegas de outros campos, que indicam que as pesquisas do Pensamento Social possuem uma falta de

\footnotetext{
${ }^{10}$ Sobre as diferentes posições na área, recomendamos as entrevistas realizadas com doze pesquisadores que ajudaram em sua consolidação. Ver: "Simpósio: cinco questões sobre o pensamento social brasileiro", organizado por Lilia Schwarcz e André Botelho (2011). Em "Um programa forte para o pensamento social", Botelho (2019a) faz uma análise cuidadosa dos resultados desse simpósio, indicando algumas tendências e desafios da área.
} 
conexões com questões e problemas mais amplos das Ciências Sociais. Não por acaso, nos últimos anos, verificamos um questionamento realizado por vários praticantes da área sobre qual seria a relevância teórica e metodológica do Pensamento Social no Brasil (MAIA, 2018; BOTELHO, 2019a).

A atualidade da área, na formulação precisa de Elide Rugai Bastos (2011, p. 52), refere-se à temática que frequentemente a animou, uma vez que "a problemática da emancipação, do direito à diferença, dos limites à liberdade, da definição da dignidade como projeto social, do reconhecimento, da exclusão/excludência" que fazem parte do debate contemporâneo, foram objetos recorrentes de reflexão entre os intelectuais brasileiros. Nessa linha, o Pensamento Social no Brasil pode ser entendido como um espaço de diálogo interdisciplinar - reunindo cientistas sociais, historiadores, críticos literários, economistas etc. - para debater problemas caros à sociedade brasileira. Concordando com o argumento de Maia (2018, p. 79, grifos nossos), "a tradição intelectual nacional não é apenas o objeto da análise, mas o horizonte contemporâneo que permite aos praticantes do campo discutir os dilemas de um processo social mais amplo". Sendo um espaço de diálogo, sugerimos que os artigos deste dossiê podem interpelar questões desenvolvidas no interior dessa importante área das Ciências Sociais brasileiras e, ao mesmo tempo, fazer com que questões da área possam encontrar novos equacionamentos a partir das fronteiras disciplinares.

\section{DILEMAS CONTEMPORÂNEOS}

Em balanço crítico recente sobre os debates da formação nacional, Elide Rugai Bastos ressaltou que o projeto da modernidade foi traído - na medida em que não existe igualdade, plena liberdade e tampouco solidariedade - o que traz inúmeras consequências para o debate teórico. ${ }^{11} \mathrm{~A}$ afirmação de Bastos parece ir de encontro à indagação que nós, organizadores, tínhamos no início do processo de composição

\footnotetext{
${ }^{11}$ A fala da professora Elide Rugai Bastos, feita na mesa "Os estudos sobre a formação do Brasil: Balanço Crítico - FFLCH - USP”, pode ser acessada através do link: https://www. youtube.com/watch?v=KoCBTgeMW3c . Acesso em 10 jun. de 2021.
} 
deste dossiê, quando procurávamos entender como a nova geração de pesquisadoras e pesquisadores tratam as interpretações do Brasil diante de um desafio bastante particular: responder aos imperativos de nossa época, que impelem a grande área das Ciências Humanas a operar com categorias específicas que dialogam com as demandas de diferentes grupos sociais como as categorias de "identidade", "representatividade e "performance" - sem, no entanto, abandonar as problemáticas não resolvidas da modernidade - como as categorias de "desigualdade", "classe", "Estadonação", dentre tantas outras -, que ainda se impõem e compõem a realidade mais imediata. Em outros termos, acreditamos que neste dossiê poderíamos entender como novas gerações que vêm pensando o país hoje têm mobilizado as diferentes interpretações do Brasil para dar conta dos problemas contemporâneos, sem necessariamente recorrer a uma perigosa redução conceitual.

Como ressaltado por Bastos, este desafio não se limita ao contexto nacional mais imediato: apesar das nossas muitas particularidades, é importante que tenhamos em vista que a ascensão de novas categorias críticas, acompanhada de um questionável abandono de conceitualizações caras à modernidade, é um problema que atinge a produção intelectual a nível global, processo este que muito diz respeito a uma reconfiguração da própria dinâmica do capitalismo ao longo dos últimos cinquenta anos. Essa, evidentemente, não é uma questão inédita, já que vem sendo estudada por autoras e autores dos mais diferentes campos do pensamento, que tentam entender estas novas configurações, seus avanços e limites.

Nas últimas décadas, por exemplo, Luc Boltanski (2013) já vem demonstrando a problemática virada dos modelos de gestão e de produção crítica no capitalismo. O autor defende que, desde meados da década de 1970, com a crise do modelo fordista, de 1973, e a contínua decadência da URSS, um modelo de dominação ideológica teria sido gradualmente substituído por aquilo que ele chama de dominação gestionária, na qual a possibilidade de ação do sujeito é explicitamente reduzida frente aos dispositivos de poder. Para o autor, esta dominação conteria o desenvolvimento de críticas radicais, já que, ao contrário de um modelo de dominação puramente ideológico - que se encontraria relacionado 
a uma adesão entusiasmada e apaixonada à ordem estabelecida -, a dominação gestionária demandaria que os indivíduos e grupos dominados "sejam realistas. Ser realista, quer dizer, aceitar as restrições, notadamente econômicas, tais como elas são, não porque sejam boas ou justas 'em si', mas porque não podem ser diferentes do que são” (BOLTANSKI, 2013, p. 450 , grifo no original).

Apesar das muitas distinções teórico-metodológicas, o diagnóstico de Boltanski se aproxima parcialmente do proposto por Slavoj Žižek (2003), que defende a existência de uma censura liberal, a qual se sustentaria em ideias como "democracia", "identidade", "guerra ao terror", dentre outras, que obnubilariam o sentido da dominação, dificultando a reflexão crítica a seu respeito. Não tão distante desta percepção estaria a noção de "realismo capitalista" de Mark Fisher, que demonstra como o sistema "vencedor" da Guerra Fria opera em diferentes níveis ideológicos - o que inclui a produção acadêmica -, apresentando-se como a única alternativa viável (FISHER, 2009). Um dos diálogos que o autor estabelece é com Wendy Brown, que tenta refletir justamente a atual natureza nãorevolucionária dos movimentos políticos, que se tornaram, gradativamente "empreendimentos não-utópicos apegados ao presente desventurado" (BROWN, 2011, p. 99, tradução nossa). A autora relaciona essa mudança de perspectiva dos movimentos políticos com as tendências do que ela entende se tratar de uma virada anti-intelectual dentro da própria produção acadêmica, principalmente - mas não exclusivamente - da academia dos Estados Unidos. Brown questiona justamente uma perigosa tendência na produção científica de privilegiar uma empiria pura e a reflexão sobre experiências de grupos individualizados, ignorando reflexões de maior profundidade teórica, assim como processos históricos que serviriam como índices para uma análise mais aprofundada dos acontecimentos sociais em curso (BROWN, 2011).

Similar crítica à falta de densidade de certos modismos acadêmicos é realizada por Enzo Traverso (2020). O autor propõe que, a partir da década de 1980, a figura do intelectual crítico perde consideravelmente sua visibilidade social devido a uma necessidade de interiorização de uma sucessão de derrotas históricas que se deram ao longo do século XX, bem 
como frente a um processo de alargamento da Indústria Cultural, que privilegia autores e perspectivas de fácil consumo, que trazem soluções e interpretações simplistas frente a problemas complexos e de difícil resolução (TRAVERSO, 2020). Se entendemos que, como propõe o autor, junto a este processo ocorre, de modo concomitante, uma gradual e crescente proletarização do intelectual, podemos observar como uma certa lógica imediatista, em muitos casos relacionada diretamente a um processo de mercantilização via Indústria Cultural, pode acabar contaminando a própria produção acadêmica, tendo em vista a evidente necessidade de garantia da existência material destes pesquisadores.

Neste ponto, entra a internet como um espaço no qual existiria, por um lado, um potencial democrático e crítico, mas, por outro, um adensamento desta supracitada lógica de simplificação da crítica. É inegável que a internet, como configurada hoje em suas redes sociodigitais, vem sendo encarada por alguns intérpretes como espaço aberto para a luta pela liberdade (CASTELLS, 2013; BENTES, 2014) - o que por si só já aponta uma alteração no sentido do conceito moderno de liberdade. Se antes, paradigmaticamente, falar em liberdade era tratar da liberdade coletiva contra todo um sistema que tornava possível a opressão, agora o termo está mais ligado ao exercício da liberdade individual de grupos específicos contra um tipo de opressão a ele restrito (BROWN, 2011). Em outros termos, a insatisfação social não seria mais direcionada contra um sistema complexo de dominação e subjugação, mas a um personagem ou a um grupo muito específico - já que este confronto direto entre grupos permitiria a melhoria imediata das condições individuais. Assim, a dinâmica das redes torna ainda mais fácil para certos grupos sociais confrontarem diretamente seus algozes e, no entanto - e é aqui que estaria a ambiguidade desta dinâmica - estes grupos continuariam servindo e alimentando a própria estrutura econômica e social que, antes, era alvo das críticas mais fundamentadas (DANTAS et al, 2014).

Além disso, a dinâmica das redes sociodigitais aprofunda $O$ diagnóstico de Traverso sobre a submissão do trabalho intelectual à lógica da Indústria Cultural. Considerando que a visibilidade e o grau de impacto da informação produzida para as redes está diretamente relacionado com 
a quantidade de posts, de likes e interações, o intelectual que, por gosto ou necessidade material, se vê na posição de produzir conteúdo para a internet, acaba se submetendo a uma lógica de produção quantitativa de informação, lógica esta que, em muitos sentidos, se distancia do necessário tempo de maturação e desenvolvimento de um pensamento crítico bem formulado - o que já foi, de diferentes maneiras, elencado por autores das mais distintas linhas de pensamento, como Adorno (2009), Boltanski (2011) e o próprio Traverso (2018). Por outro lado, guardados os limites da atual configuração da internet, é inegável que ela também vem dando voz a grupos dissidentes que historicamente tiveram suas narrativas apagadas, inclusive dentro do ambiente universitário. Também é um espaço que colabora para um melhor aproveitamento e exploração de materiais de difícil acesso, aspecto este que certamente vem possibilitando que autoras e autores abordem objetos de estudo já clássicos a partir de um olhar renovado, como sugerem Antonio Brasil Jr., Luiz Carlos Jackson e Marcelo Paiva (2020, p. 233):

\begin{abstract}
Algumas possibilidades passam, por exemplo, pela exploração de fontes primárias antes de difícil acesso e hoje acessíveis ao pesquisador na tela do computador, pelo interesse criativo por autores e autoras tidos como "menores", pela exploração de obras menos conhecidas, pela reconstrução de contextos mais recentes, pela análise orientada por processos políticos contemporâneos (feminismo, movimento negro etc.).
\end{abstract}

Todos estes pontos elencados até o momento servem ao nosso argumento para demonstrar em qual contexto global que a nova geração de pesquisadoras e pesquisadores de hoje tem procurado refletir o Brasil e suas interpretações. No entanto, apesar da relevância destes pontos, se estamos falando de interpretações do Brasil, não podemos perder de vista as particularidades do contexto nacional, que são incontornáveis para pensar essas novas produções, inclusive as especificidades dos artigos que compõem o presente dossiê. Apesar de todos os desafios enfrentados pelo pensamento crítico, a nível global, e pela universidade brasileira, em 
particular, a academia ainda é um espaço de produção crítica, liberdade de pensamento e renovação de perspectivas.

Se, como indicamos, o cânone vem sendo repensado a partir da recuperação de autoras e autores tidos como menos conhecidos, assim como a partir de questões caras aos processos políticos contemporâneos, certamente a política de cotas raciais e as diferentes ações afirmativas implantadas nas principais universidades brasileiras ao longo das últimas duas décadas tiveram um papel decisivo neste processo de renovação (CAMPOS; GOMES, 2017). A participação ativa de jovens pesquisadoras e pesquisadores que, até pouco tempo, tinham baixa entrada no cenário universitário, ampliou o diálogo e abriu novas questões sobre temas e intérpretes clássicos. Ou seja, o crescente interesse de estudo sobre a questão racial por parte das novas pesquisas, assim como o interesse de explorar autoras e autores pouco abordados nos currículos, é causado em alguma medida pela renovação da universidade pelas ações afirmativas. Em síntese, ainda que os estudos sobre relações raciais no país sejam um dos mais antigos e prolíficos campos das ciências humanas no Brasil, é inegável que a implementação de cotas raciais remodelou as pesquisas da área (CAMPOS; GOMES, 2017; LIMA; CAMPOS, 2020).

Como já indicamos, os textos que compõem o presente dossiê certamente dão sinal desta remodelação das interpretações do Brasil: é notável como a maior parte dos trabalhos aqui reunidos tratam justamente da questão racial a partir de uma perspectiva renovada. Além disso, a leitura em conjunto dos artigos destes jovens pesquisadores parece trazer uma solução interessante ao dilema que coloca, de um lado, as relevantes e urgentes pautas mais imediatas e atuais e, de outro, as interpretações e questões caras à modernidade: ao articularem questões contemporâneas a autores que pensam a modernidade vista a partir da periferia, e ao tentarem renovar e repensar o cânone, os artigos do dossiê mostram que as questões que são tratadas, de modo simplista, muitas vezes como "novas" e "pósmodernas", na verdade são problemáticas constitutivas da modernidade. Logo, ao invés de operarem com categorias estanques e simplificações imediatistas, a leitura em conjunto dos trabalhos aqui publicados, permitenos olhar para o nosso tempo e entender que as questões mais urgentes 
que se impõem são justamente decorrentes do fato de que os princípios da modernidade ainda não se completaram.

Porém, antes de tratarmos das particularidades de cada um dos artigos aqui publicados, acreditamos ser importante falar brevemente sobre o desafio de organizar um dossiê em meio à crise sanitária gerada pela Covid-19. Como organizadores desta edição, já prevíamos que perceberíamos algum impacto da pandemia no processo de desenvolvimento deste número da revista Temáticas. Portanto, não foi surpresa quando notamos que havia uma discrepância entre o número de artigos escritos por autoras e por autores que recebemos ao longo do período de submissão. Isso se agravou ao fim do processo de avaliação cega, quando percebemos que nenhum dos artigos que iria compor o dossiê era escrito por mulheres, salvo esta apresentação, escrita pelas organizadoras Beatriz Malcher e Maria Caroline M. Tresoldi, junto com Karim Helayel, e a entrevista que Helayel e Tresoldi fizeram com Elide Rugai Bastos. Infelizmente esta sub-representação de gênero não se limita ao presente dossiê, tratando-se de uma problemática mais ampla que diz respeito à produção acadêmica das mais diversas áreas, no Brasil e no mundo.

Apesar de sempre ter havido uma sub-representação de autoras mulheres em periódicos científicos, mesmo com a grande participação e influência de pesquisadoras nos principais centros de pesquisa do mundo (TEELE; THELEN, 2017; CANDIDO; CAMPOS, 2020), a pandemia parece ter acentuado este problema. Nos primeiros meses de crise global, algumas reportagens internacionais já lançavam luz sobre o caso: uma matéria do Inside Higher Edrealizou um levantamento preliminar, indicando a possibilidade da produtividade entre pesquisadoras ser reduzida por conta do isolamento social (FLAHERTY, 2020). Alguns meses depois, uma pesquisa publicada no site The Lily, ressaltou a divisão desigual de gênero, demonstrando uma alteração do fluxo editorial durante a quarentena, já que o número de artigos submetidos por mulheres havia decrescido consideravelmente, enquanto, por outro lado, homens estavam submetendo 50\% mais artigos do que antes da pandemia (KITCHENER, 2020). 
Estes dados geraram interesse em pesquisadoras e pesquisadores no Brasil, que procuraram pensar o impacto do isolamento social na produção científica de mulheres pesquisadoras. Marcia Rangel Candido e Luiz Augusto Campos fizeram um importante levantamento sobre a submissão de artigos à revista Dados no período do primeiro semestre de 2016 até o segundo semestre de 2020, e diagnosticaram que, ainda que 2020 tenha se iniciado com um número de submissões de autoras próximo à média geral de $40,8 \%$, no segundo trimestre essas submissões teriam atingido o menor patamar do período analisado, com apenas $28 \%$ de autoras assinando os artigos submetidos (CANDIDO; CAMPOS, 2020). O caso parece se agravar quando tratamos de autoras mães. A partir de uma pesquisa qualitativa feita com 15 mil cientistas, entre discentes de pós-graduação, pós-doutorandas(os) e docentes brasileiras(os), o coletivo Parent in Science concluiu que apenas 4,1\% das mães entrevistadas afirmava estar conseguindo dar conta do trabalho remoto. ${ }^{12}$ Esta pesquisa parece ir ao encontro dos resultados publicados por Katie Langin na revista Science, em fevereiro de 2021, que mostra o impacto negativo que um ano de pandemia teve na produção científica de mães nas mais diversas áreas do conhecimento (LANGIN, 2021).

Deste modo, acreditamos que o baixo número de artigos submetidos por mulheres para compor o presente dossiê reforça o problema de disparidade de gênero e de sub-representação das mulheres nos periódicos científicos, problema este agravado pela pandemia. A não participação de autoras mulheres neste dossiê - para além de suas duas organizadoras aponta para um problema mais geral e extremamente grave que deve ser colocado em evidência e tratado com a devida seriedade, por ser uma questão estrutural que a academia, em nível nacional e internacional, ainda não conseguiu superar.

\footnotetext{
${ }^{12}$ O resultado desta pesquisa foi publicado diretamente no site do coletivo (https://www. parentinscience.com/) e gerou, como consequência, uma carta aberta publicada na revista Science (STANISCUASKI et al, 2020).
} 


\section{A COMPOSIÇÃO DO DOSSIÊ}

Feito este percurso por alguns temas e questões que atravessam o dossiê Interpretações do Brasil e dilemas contemporaneos e impactaram sua organização, podemos agora abordar diretamente os artigos que o compõem e suas importantes contribuições para pensar e atualizar as interpretações do Brasil - principalmente a partir e por meio do debate racial. Como já indicamos, o dossiê é composto por um conjunto variado de temas, objetos e abordagens teórico-metodológicas. São aqui estudadas ideias, intelectuais e tradições intelectuais, bem como conceitos que forjam modos de sentir, atuar e interpretar o país. Há, ainda, uma discussão sobre o alargamento da noção de textos - como revela, por exemplo, a análise de tweets, desenvolvida em um dos artigos, ou o artigo que toma as telenovelas como objeto de estudo.

O dossiê abre com o artigo $A$ força do concreto: a esquerda no pré-golpe de 1964 e o ornitorrinco de Caio Prado Jr., no qual Dario de Negreiros se debruça fundamentalmente sobre o livro A revolução brasileira (1966), de Caio Prado Jr., procurando efetuar uma análise interna de suas formulações, de modo a perscrutar a potência teórica heurística de seus desdobramentos em trabalhos que passam por Fernando Novais e chegam até Francisco de Oliveira. Se, de um lado, como sustenta Negreiros, Caio Prado Jr. teria demonstrado os limites analíticos das teses do Partido Comunista Brasileiro (PCB) a respeito dos supostos resquícios feudais de nossa formação e do caráter revolucionário de uma burguesia nacional supostamente orientada por valores democráticos, de outro lado, percebendo que o capitalismo periférico se desenvolve a partir de seus elementos de "atraso", teria antecipado diagnósticos de Francisco de Oliveira em seu $A$ economia brasileira: crítica à razãa dualista (1973) e, contemporaneamente, em $O$ Ornitorrinco (2003). O exercício analítico efetuado pelo autor reforça o potencial de algumas teses clássicas, que ainda têm muito a dizer sobre os impasses do nosso tempo.

$\mathrm{Na}$ sequência, temos o artigo O olhar sociológico de Otávio Dulci sobre a questão regional. Antonio Cardoso e Lucas Saraiva procuram empreender uma análise da perspectiva sociológica do cientista político Otávio Dulci a 
respeito da questão regional, levando em consideração a problemática da constituição da burguesia brasileira, enfatizando o caso de Minas Gerais, nos anos posteriores à instauração do Governo Provisório de Getúlio Vargas. Os autores sustentam que a contribuição teórica de Dulci teria sido a de compreender e explicar a atualidade, mobilizando a história como recurso em suas formulações sobre as singularidades e experiências regionais, valendo-se ainda de tipologias que pudessem ser utilizadas em análises de contextos distintos entre si. Aqui, temos uma reflexão que não se limita a apresentar Otávio Dulci como um intérprete de clássicas interpretações do país - especialmente as de Florestan Fernandes -, mas como um autor que, a partir de um diálogo rigoroso com parte da tradição intelectual brasileira, forjou uma visão própria do país e de seus desafios regionais. Assim, o artigo lança luz sobre uma interpretação que permite ampliar o cânone do que entendemos como interpretações do Brasil e como Pensamento Social Brasileiro.

$\mathrm{O}$ artigo $A$ democracia racial no pensamento de Guerreiro Ramos: um balanço dos comentadores, abre as discussões do dossiê que tratam mais diretamente da questão racial e mostram como a violência e o racismo são traços definidores da sociedade brasileira. No artigo, Alan Caldas e Nikolas Gustavo Palliser Silva realizam um balanço crítico das interpretações acerca do significado, do lugar e da função do conceito de democracia racial no pensamento de Alberto Guerreiro Ramos. Os autores dialogam com algumas das principais intepretações contemporâneas da obra de Ramos - como as desenvolvidas por Marcos Chor Maio, Antonio Sérgio Alfredo Guimarães, Muryatan Santana Barbosa e Luiz Augusto Campos -, e argumentam que o conceito de democracia racial utilizado pelo sociólogo baiano foi apropriado da intelectualidade acadêmica pelos intelectuais militantes negros dos anos de 1940 e 1950. Para os autores, o conceito mobilizado por Ramos opera uma mudança importante em relação a alguns dos sentidos atribuídos por intelectuais como Gilberto Freyre, pois se trata tanto de um projeto político de integração das populações negras à estrutura social competitiva então em emergência, quanto de uma "terapêutica das subjetividades colonizadas" a partir da 
estética da negritude. Recuperando os sentidos de tal conceito, Caldas e Silva apostam em sua potência para o debate racial contemporâneo.

Em "O racismo é velado no Brasil": o discurso da miscigenação e a ocultação do óbvio, Douglas Vinícius Souza e Silva desenvolve uma contundente crítica à parte da tradição intelectual brasileira - em especial, a nomes como Sílvio Romero, Euclides da Cunha, Gilberto Freyre, Sérgio Buarque de Holanda e em alguma medida Antonio Candido -, cujas ideias teriam desempenhado um papel significativo na consolidação do discurso da miscigenação como elemento central da identidade nacional. No argumento do autor, esse discurso cristalizado na cultura brasileira confere substância à tese de que o racismo se manifesta de modo velado no país, "disfarçado sob uma aparente cordialidade do povo brasileiro". Procurando reconstruir polêmicas recentes sobre o debate racial, o artigo trata especialmente de ideias difundidas por alguns veículos de comunicação e alguns líderes políticos (no caso destes, recorta-se materiais como tweets), e mostra como certos discursos contribuem para que se desvie o olhar das características violentas do racismo brasileiro. A argumentação de Silva, ao enfatizar como o mito da democracia racial continua presente na vida pública brasileira, é conduzida a partir de um fino diálogo com nomes contemporâneos, como Lilia Schwarcz, Djamila Ribeiro, Emicida e Jones Manoel, o que não deixa de revelar um interesse do pesquisador pelo alargamento da categoria intérpretes do Brasil.

Assim como Douglas Silva, Alan Osmo, em $A$ literatura diante de massacres cometidos pelo Estado brasileiro: aproximações entre Euclydes da Cunha e Racionais MC's, também procura lançar um olhar renovado sobre o cânone das interpretações do Brasil. Aproximando as formulações de Euclides da Cunha em Os sertões (1902), com o álbum Sobrevivendo no inferno (1997), especialmente a canção "Diário de um detento", dos Racionais MC's, o autor aponta para a continuidade histórica dos crimes perpetrados pelo Estado brasileiro, que contaram com enorme aparato repressivo e tentativas de "esquecimento oficial". De modo mais preciso, Osmo chama a atenção, ao discutir os respectivos massacres tratados pelo ensaísta e pelos rappers - Canudos (1896-7) e Carandiru (1992) -, para a importância da arte no processo de construção de uma memória histórica sobre a 
violência que marca os processos sociais no país. Assim, este trabalho permite repensar a própria categoria de intérpretes do Brasil, ampliando-a para além dos limites da academia e da literatura erudita. Ou seja, mesmo que os estudos clássicos sobre as interpretações do Brasil, nas mais diversas áreas do conhecimento, incorporem a literatura e a música como formas de interpretação social, aqui há uma originalidade em deslocar esses gêneros para o lugar de tribunal da história, isto é, como memória e expressão de vozes historicamente silenciadas.

O alargamento da categoria de intérpretes do Brasil também é elaborado por Gabriel Delphino e Thiago Campos da Silva no artigo Pensamento negro em debate: as ideias de Ronilso Pacheco e Emicida. Os autores estabelecem um interessante diálogo entre o pensamento do pastor Ronilso Pacheco e o do rapper Emicida, relacionando-os às interpretações propostas por diferentes expoentes do pensamento negro no país como Guerreiro Ramos, Clóvis Moura, Abdias do Nascimento e Sueli Carneiro -, no intuito de levarem ao primeiro plano da análise sujeitos marginalizados e reflexões ignoradas por narrativas hegemônicas. O texto cumpre um papel central no dossiê, na medida em que ressalta a importância das interpretações de pensadores negras e negros para a compreensão e explicação da formação social brasileira. Debatendo as ideias de um pastor e de um rapper, os autores apontam para o caráter interdisciplinar dos estudos sobre as interpretações do Brasil, destacando, ainda, a importância de diferentes abordagens sobre o mundo social para a problematização de processos históricos, acabados e em curso, possibilitando, desta forma, novos olhares sobre dilemas cotidianos, como o racismo estrutural, o genocídio negro, a ampliação das desigualdades raciais e sociais, dentre outros.

O último artigo que integra este dossiê é Representação do negro na velhice: uma narrativa de exceção em telenovelas. Nele, Valmir Moratelli discute a presença e a ausência de atores negros e de atrizes negras no audiovisual brasileiro, em particular da TV Globo, uma das emissoras públicas de maior alcance no país. Se há poucas personagens negras nas telenovelas brasileiras, o que poderíamos dizer sobre as personagens negras idosas? Partindo do pressuposto de que as telenovelas cumprem papéis 
destacados na circulação e rotinização de ideias no país, o autor mostra que podemos tratar esse grupo como "narrativa de exceção" pois, além de vermos poucas personagens negras idosas, quando elas existem, exercem papéis de coadjuvantes. Para construir sua crítica, Moratelli dialoga com interpretações tecidas por Florestan Fernandes, Lélia Gonzalez, Abdias do Nascimento, Sueli Carneiro, entre outros, e aposta na abertura das telenovelas para um tratamento mais cuidadoso da questão racial e da temática da velhice.

Além destes artigos, o dossiê também conta com uma interessante resenha escrita por Mateus Sanches Duarte a respeito do livro $A$ cidade porosa (2019) de Bruno Carvalho, que pensa as transformações urbanas da Cidade Nova, no Rio de Janeiro, mostrando como elas sintetizam as contradições mais prementes da dinâmica urbana da capital fluminense. $\mathrm{O}$ autor destaca como Bruno Carvalho aciona o conceito de porosidade para pensar seu objeto de pesquisa, utilizando-o como categoria analítica que valoriza o caráter espacial. Assim, na "cidade porosa" reside o encontro das diferenças com os processos de modernização e urbanização que aprofundam a segregação espacial, social e racial. Um tema inescapável, não apenas para pensar o Rio de Janeiro durante os séculos XIX e XX, mas também outras partes do Brasil, com ecos na contemporaneidade.

Por fim, contamos com uma esclarecedora entrevista com uma das principais intérpretes do país, Elide Rugai Bastos. A conversa, que ocorreu por videochamada em maio de 2021, foi conduzida por dois dos organizadores deste dossiê, Karim Helayel e Maria Caroline M. Tresoldi. Nela, temos uma visão nuançada do percurso intelectual e da obra da professora, orientadora, pesquisadora e intérprete do país. Bastos conta um pouco sobre sua trajetória de pesquisa na área de Pensamento Social no Brasil, da qual é uma das "fundadoras", por assim dizer, e faz um balanço da área no quadro mais amplo das Ciências Sociais. Como a leitora e o leitor notarão, a entrevistada chama a atenção para a atualidade de alguns intérpretes do país para uma reflexão em torno de questões centrais no debate público brasileiro.

Em suma, esperamos que este dossiê colabore para a apreensão dos alcances e limites de algumas interpretações do Brasil e para o 
alargamento do cânone, contribuindo ainda com as discussões em torno do "pequeno grande mundo" do Pensamento Social no Brasil, para usar a formulação de Brasil Jr., Jackson e Paiva (2020). Também esperamos que os manuscritos aqui reunidos ajudem a pensar alguns dos desafios do Brasil contemporâneo. Afinal, como mencionamos nesta apresentação, os momentos de tensão social podem colaborar para que tenhamos uma visão de conjunto da sociedade. $\mathrm{Na}$ ausência de intérpretes - sejam eles progressistas ou conservadores, acadêmicos ou artistas, clássicos ou contemporâneos -, a compreensão dos processos sociais em curso fica seriamente comprometida. Boa leitura!

\section{REFERÊNCIAS}

ADORNO, Theodor W. Dialética Negativa. Rio de Janeiro: Zahar, 2009.

BASTOS, Elide Rugai. A questão racial e a revolução burguesa. In: D’INCAO, Maria Ângela (Org.). O saber militante: ensaios sobre Florestan Fernandes. Rio de Janeiro: Paz e Terra; São Paulo: UNESP, 1987, p. 140-150.

BASTOS, Elide Rugai. Pensamento social da escola sociológica paulista. In: MICELI, Sérgio (org). O que ler na ciência social brasileira, 1970-2002. São Paulo/Brasília: Anpocs/Sumaré, 2002, p. 183-232.

BASTOS, Elide Rugai. As criaturas de Prometeu: Gilberto Freyre e a formação da sociedade brasileira. São Paulo: Global, 2006.

BASTOS, Elide Rugai. Atualidade do pensamento social brasileiro. Revista Sociedade e Estado. Brasília, v.26, n.2, p. 51-70, maio/agosto 2011.

BASTOS, Elide Rugai. A história nunca se fecha. Sociologia \& Antropologia. Rio de Janeiro, v.10, n. 2, p. 677-694, maio-agosto 2020.

BASTOS, Elide Rugai; BOTELHO, André. Horizontes das ciências sociais: pensamento social brasileiro. In: MARTINS, Carlos Benedito; MARTINS, Maria Helena de Souza (orgs.). Horizontes das ciências sociais no Brasil: sociologia. São Paulo: ANPOCS, 2010, p. 475-496. 
BENTES, Ivana. Redes colaborativas e o pensamento P2P: a dobra brasileira. P2P \& inovação. Rio de Janeiro, v. 1, n. 1, setembrodezembro 2014.

BOLTANSKI, Luc. On Critique: a sociology of emancipation. Cambridge: Polity Press, 2011.

BOLTANSKI, Luc. Sociologia da crítica, instituições e o novo modo de dominação gestionária. Sociologia \& Antropologia. Rio de Janeiro, v. 3, n. 6, p. $441-463$, nov. 2013.

BOTELHO, André. O retorno da sociedade: política e interpretações do Brasil. Petrópolis: Vozes, 2019a.

BOTELHO, André. Patrimonialismo brasileiro. In: SCHWARCZ, Lilia; STARLING, Heloisa (Orgs.). Dicionário da República: 51 textos críticos. São Paulo: Companhia das Letras, 2019b, p. 276-282.

BOTELHO, André; SCHWARCZ, Lilia. Esse enigma chamado Brasil: apresentação. In: BOTELHO, André; SCHWARCZ, Lilia (orgs.). Um enigma chamado Brasil: 29 intérpretes e um país. São Paulo: Companhia das Letras, 2009, p. 11-17.

BOTELHO, André; BRASIL JR., Antonio. A revolução burguesa no Brasil: cosmopolitismo sociológico e autocracia burguesa. In: FERNANDES, Florestan. A revolução burguesa no Brasil: ensaio de interpretação sociológica. São Paulo: Editora Contracorrente, 2020, p. 7-19.

BRANDÃO, Gildo Marçal. Linhagens do pensamento político brasileiro. São Paulo: Editora Hucitec, 2007.

BRASIL JR., Antonio. As ideias como forças sociais: sobre uma agenda de pesquisa. Sociologia \& Antropologia. Rio de Janeiro, v. 5, n. 2, p. 553574, agosto 2015. 
BRASIL JR., Antonio; JACKSON, Luiz Carlos; PAIVA, Marcelo. Pensamento Social no Brasil: um pequeno grande mundo. In.: CAMPOS, Luiz Augusto; CHAGURI, Mariana; FLEURY, Lorena. Ciências sociais hoje: sociologia. São Paulo: Zeppelini Publishers, 2020, p. 221-257.

BROWN, Wendy. Edegework: critical essays on knowledge and politics. Princeton, Oxford: Princeton University Press, 2011.

CANDIDO, Antonio. O significado de Raízes do Brasil. In: HOLANDA, Sérgio Buarque de. Raízes do Brasil. São Paulo: Companhia das Letras, 1995, p. 9-21.

CANDIDO, Marcia Rangel; CAMPOS, Luiz Augusto. Pandemia reduz submissões de artigos acadêmicos assinados por mulheres. Blog DADOS, 2020. Disponível em: http://dados.iesp.uerj.br/pandemiareduz-submissoes-de-mulheres/. Acesso em: 01 jun. 2021.

CARDOSO, Fernando Henrique. Pensadores que inventaram o Brasil. São Paulo: Companhia das Letras, 2013.

CARVALHO, Lucas; BRASIL Jr. Antonio. Mapeando a área de pensamento social no Brasil: uma análise preliminar de sua produção em artigos. Revista Eletrônica de Comunicação, Informação e Inovação em Saúde, v. 14, n.3, p. 597-618, 2020.

CASTELLS, Manuel. Redes de indignação e esperança: movimentos sociais na era da internet. Rio de Janeiro: Zahar, 2013.

CAMPOS, Luiz Augusto; GOMES, Ingrid. Relações raciais no Brasil contemporâneo: uma análise preliminar da produção em artigos acadêmicos dos últimos vinte anos (1994-2013). Revista Sinais Sociais, v. 11, p. 85-116, 2017.

CHALOUB, Jorge; LIMA, Pedro Luiz. Interpretações do Brasil contemporâneo. Mediações. Londrina, v. 23, n. 2, p. 14-39, maioagosto 2018. 
DANTAS, Marcos et al. Trabalho gratuito nas redes: de como o ativismo de $99 \%$ pode gerar ainda mais lucros para 1\%. Liinc em Revista, Rio de Janeiro, v. 10, n. 1, p. 22-43, maio 2014.

FISHER, Mark. Capitalist realism. Washington: O Books, 2009.

FLAHERTY, Colleen. No Room of One's Own. Inside Higher Ed. Abril, 2020. Disponível em: https://www.insidehighered.com/ news/2020/04/21/early-journal-submission-data-suggest-covid-19tanking-womens-research-productivity. Acesso em: 10 jun. 2021.

JOSIOWICZ, Alejandra; BRASIL JR., Antonio. Pensamento social e pesquisa informacional: o caso da Biblioteca Virtual do Pensamento Social (BVPS). Revista Brasileira de Sociologia, v.7, n.16, p. 5-28, maioagosto 2019.

KITCHENER, Caroline. Women academics seem to be submitting fewer papers during coronavirus. "Never seen anything like it," says one editor. The Lilly. 2020. Disponível em: https://www.thelily.com/women-academics-seem-to-be-submitting-fewer-papers-during-coronavirus-never-seen-anything-like-it-says-one-editor/. Acesso em: 10 jun. 2021.

LANGIN, Katie. Pandemic hit academic mothers hard, data show. Science, v.371, issue 6530, 2021.

LIMA, Márcia; CAMPOS, Luiz Augusto. Inclusão racial no Ensino Superior: impactos, consequências e desafios. Novos Estudos Cebrap (online), v. 39, p. 245-254, 2020.

MAIA, João Marcelo E. Ao sul da teoria: A atualidade teórica do pensamento social brasileiro. Sociedade e Estado. Brasília, v. 26, n. 2, p. 71-94, 2011.

MAIA, João Marcelo E. Os sentidos da tradição: um estudo de caso no Pensamento Social Brasileiro. Sociologia \& Antropologia. Rio de Janeiro, v. 5, n. 2, p. 535-551, maio/agosto 2015. 
MAIA, João Marcelo E. Qual é a relevância teórica do pensamento social no Brasil? In: CHAGURI, Mariana; MEDEIROS, Mário (org). Rumos do Sul: periferia e pensamento social. São Paulo: Alameda, 2018, p. 77-88.

RICUPERO, Bernardo. Sete lições sobre as interpretações do Brasil. São Paulo: Alameda, 2008.

RICUPERO, Bernardo. Patrimonialismo: usos de um conceito. In: BOTELHO, André; STARLING, Heloisa. (orgs.). República e democracia: impasses do Brasil contemporâneo. Belo Horizonte: Editora UFMG, 2017, p. 263-275.

SCHWARCZ, Lilia; BOTELHO, André. Simpósio: cinco questões sobre o pensamento social brasileiro. Lua Nova, v.82, p. 139-159, 2011.

STANISCUASKI, Fernanda et al. Impact of COVID-19 on academic mothers. Science, v. 368, Issue 6492, p. 724, May, 2020.

TEELE, Dawn Langan; THELEN, Kathleen. Gender in the Journals: Publication Patterns in Political Science. PS: Political Science \& Politics, v. 50, Issue 2, p. 433-447, april 2017.

TRAVERSO, Enzo. Melancolia de esquerda: marxismo, história e memória. Belo Horizonte: Editora Âyiné, 2018.

TRAVERSO, Enzo. Onde foram parar os intelectuais? Belo Horizonte: Editora Âyiné, 2020.

WERNECK VIANNA, Luiz. Weber e a interpretação do Brasil. In: SOUZA, Jessé. (Org.). O malandro e o protestante: a tese weberiana e a singularidade cultural brasileira. Brasília: Editora UnB, 1999, p. 173194.

WERNECK VIANNA, Luiz. Raymundo Faoro e a difícil busca do moderno no país da modernização. In: BOTELHO, André; SCHWARCZ, Lilia. (Orgs). Um enigma chamado Brasil: 29 intérpretes e um país. São Paulo: Companhia das Letras, 2009, p. 364-377.

ŽIŽEK, Slavoj. Bem-vindo ao deserto do real!. São Paulo: Boitempo Editorial, 2003. 